\title{
Gemination Involving Mandibular Third Molar - A Rare Case Report and Review of Literature
}

\author{
Amal Ahmed Khawaji ${ }^{1}$, Maryam Mohammed Maashi², Nedaa Hasan Alhazmi ${ }^{3}$, Fareedi Mukram Ali ${ }^{4}$
}

1, 2,3,4 Department of Oral \& Maxillofacial Surgery, College of Dentistry, Jazan University, Jazan (KSA), Saudi Arabia.

\section{INTRODUCTION}

Developmental anomalies affecting the teeth are because of disturbances in the formation of dental lamina and the germ of tooth. These can be due to inherited, congenital, idiopathic or acquired causes and can lead to anomalies of tooth number, shape, size or structure.1,2 If one tooth germ by division forms two equal teeth, the term gemination is used. It can be partial or complete (bifid crown). In complete division, two separate crowns with their own pulp chambers and one common root are formed. ${ }^{3}$ Enlarged tooth produced by incomplete division of a single bud of tooth is called as gemination. These developmental disturbances are not ordinary findings in regular dental practice. It is also called in literature by various terms such as "double formations", "fused teeth" or "joined teeth".4 Brook and winter to avoid terminology confusion called this incidence as "connated teeth" or "double teeth". 5

Severity of gemination is based on the phase of formation of the tooth affected. The incidence of this type of developmental anomalies was reported to be less than 1 $\%{ }^{6-8}$ Appropriate diagnosis in early stages can prevent future problems and postsurgical complications, and can also facilitate the clinical management of such cases. ${ }^{9-11}$ Here, a rare case study of gemination involving mandibular third molar is discussed.

\section{PRESENTATION OF CASE}

A 30-year-old male patient presented with a chief complaint of pain and swelling in the mandibular left posterior region since 1 to one and half month. The patient had no significant medical or dental history. Clinical examination showed pain in relation to permanent mandibular third molar on left side. The tooth had presence of deep occlusal caries. There was presence of slight swelling on buccal aspect in relation to this tooth.

Ortho-Pantomo-Gram (OPG) showed a radio-opaque crown structure of tooth attached to the distal surface of vertically impacted mandibular third molar on left side. The tooth was showing presence of deep caries. Dentin and enamel structures can be seen in the distal attached crown structure. (Fig. 1)
Corresponding Author: Dr. Fareedi Mukram Ali, Department of Oral \& Maxillofacial Surgery, College of Dentistry, Jazan University, Jazan (KSA), Saudi Arabia.

E-mail:faridi17@rediffmail.com

DOI: $10.14260 /$ jemds/2020/746

How to Cite This Article:

Khawaji AA, Maashi MM, Alhazmi NH, et al. Gemination involving mandibular third molar: a rare case report and review of literature. $J$ Evolution Med Dent Sci 2020;9(45):3399-3401, $10.14260 /$ jemds/2020/746

Submission 06-08-2020,

Peer Review 30-09-2020,

Acceptance 06-10-2020,

Published 09-11-2020.

Copyright (C) 2020 JEMDS. This is an open access article distributed under Creative Commons Attribution License [Attribution 4.0 International (CC BY 4.0)] 


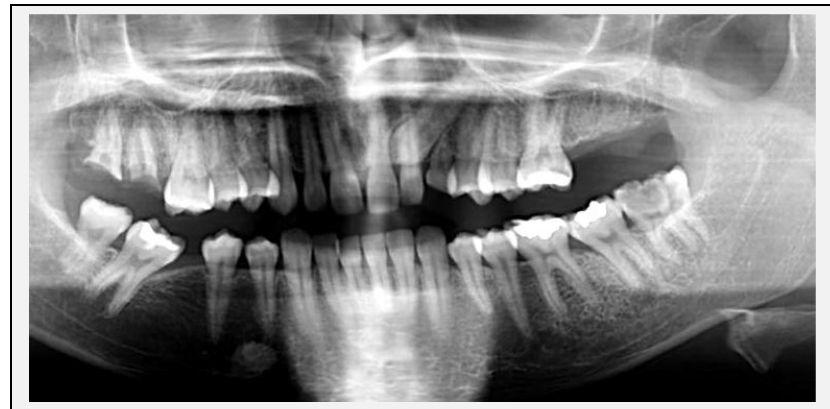

Figure 1. OPG of the Patient Showing Gemination of the Mandibular Third Molar of Left Side Showing Two Crowns and Three Roots

Based on the OPG findings, diagnosis of gemination of the mandibular third molar of left side was made. Also differential diagnosis of fusion of the supernumerary tooth or distomolar to the third molar was taken into the consideration.

As the tooth was symptomatic, it was extracted under local anaesthesia. The extracted tooth specimen consisted of two crown-like structures mesial and distal. The distal crown was attached to the mesial crown at an angulation. The distal crown had two cusps and they were of unequal size. The roots showed atypical morphology. (Fig. 2) Based on the clinical, radio graphical and extracted tooth specimen study, the tooth was determined to be gemination of mandibular third molar of left side.

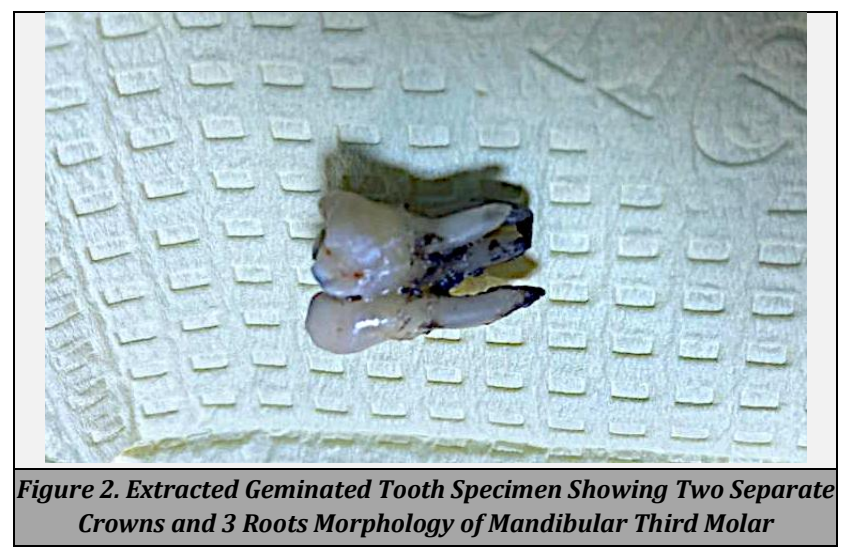

\section{DIFFERENTIAL DIAGNOSIS}

Gemination and fusion are often confusing and should be differentiated. Mader's rule of "Two Tooth" is useful for fusion and gemination differentiation. If an abnormal tooth is counted single and the teeth number in the arch is less, than fusion is measured. But, when the involving tooth is considered as one and the teeth number count in arch is normal, then considered as gemination or there is also possibility of fusion among supernumerary and normal teeth. Gemination is frequently seen in the maxilla, whereas fusion is commonly seen in the mandible. ${ }^{13,17}$

\section{DISCUSSION}

According to previous studies, gemination occurs more commonly involving primary teeth $(0.5 \%)$ than the permanent dentition (0.1\%). The gemination involving bilateral teeth can be present in $0.02 \%$ in permanent and deciduous dentitions and more incidence seen in the Mongolians (5 \%) than the Caucasians (0.5\%). 2,12 The present case was involving permanent mandibular third molar.

\section{Aetiology}

The exact pathogenesis of gemination is unknown. Environmental factors like trauma, systemic diseases, vitamin deficiencies and genetic predilection were considered as possible causes. ${ }^{13}$ According to Grover \& Lorton, ${ }^{14}$ the pathogenesis lies in the metabolic disturbances taking place during morpho-differentiation stage of the tooth germ. This condition can have a familial tendency. Gemination can be connected with syndromes like chondroectodermal dysplasia and achondrodysplasia. ${ }^{13,15,16}$

\section{Location}

The most common site of occurrence is in maxillary primary incisors and canines. ${ }^{2}$ In the present case, the mandibular third molar was presented with an anomalous crown structure and three rooted morphology. According to Guerisoli et al ${ }^{18}$ who analysed 114 cases of mandibular third molars, $0.9 \%$ showed three root morphology while Sidow et al ${ }^{19}$ reported the same in $5 \%$ of his cases.

\section{Shape}

Often the supernumerary teeth are somewhat unusual, or cone shaped and therefore fusion among normal and supernumeraries will demonstrate difference in the two halves of the connected crowns. But, in geminated teeth the two halves of the connected crowns are mirror images. ${ }^{20,21}$ In the present case the tooth showed atypical morphology.

\section{Radiographs}

Radiographs are commonly taken for the assessment of the level of abnormality. ${ }^{2}$ CBCT gives a 3-dimensional picture of the complex anatomy, thus the clinician gets help to understand the root canal better, but its use should be judicious and weighed against risk-benefit considerations. ${ }^{22,23}$

\section{Clinical Considerations}

Gemination when present in the anterior region is an aesthetic issue because of their abnormal morphology. Geminated teeth can be more prone for periodontal diseases, caries and spacing problems. The peculiar periodontal problem in these teeth happens because of the presence of grooves or fissures in the union between the involved teeth. If the grooves are deep extending to subgingival region, the plaque accumulation is quite high. Compulsory oral hygiene should be present to preserve health of periodontium. Restorations for deep grooves can decrease the possibility of caries. Also, gemination can influence interdigitation of teeth, alignment and arch symmetry resulting in crowding of teeth, delayed eruption and midline deviation. ${ }^{23-24}$ The present tooth showed presence of 
deep occlusal caries which can be due to the complexity in oral hygiene maintenance because of presence of geminated tooth.

\section{CONCLUSIONS}

Dental practitioners must be well-versed with such morphological variations and should be able to diagnose and manage such anomalies as they may require some modification in the usual management protocol. So, a cautious observance of geminated teeth is suggested. A thorough case history, clinical and radiological assessment can give essential information necessary for the diagnosis. Clinicians should constantly think about the opportunity of conservative management.

Financial or other competing interests: None.

Disclosure forms provided by the authors are available with the full text of this article at jemds.com.

\section{REFERENCES}

[1] Neves AA, Neves MLA, Farinhas JA. Bilateral connation of permanent mandibular incisors: a case report. Int J Paediatr Dent 2002;12(1):61-5.

[2] Hamesh G, Ashna BR, Vengal M. Bilateral gemination: a case report. Int J Oral Health Med Res 2016;2(5):112-5.

[3] Venkatesh A, Goel S, Wadhwan V, et al. Gemination of a mandibular third molar: a rare case report. SRM J Res Dent Sci 2016;7(2):121-3.

[4] Turkaslan S, Gokçe HS, Dalkız M. Esthetic rehabilitation of bilateral geminated teeth: a case report. Eur J Dent 2007;1(3):188-91.

[5] Brook AH, Winter GB. Double teeth. A retrospective study of 'geminated' and 'fused' teeth in children. Br Dent J 1970;129(3):123-30.

[6] Ferreira-Junior O, de Avila LD, da Silva Sampieri MB, et al. Impacted lower third molar fused with a supernumerary tooth -- Diagnosis and treatment planning using conebeam computed tomography. Int $\mathrm{J}$ Oral Sci 2009:1(4);224-8.

[7] Talla HV, Adamala SR, Surapaneni S, et al. Mandibular third molar gemination: a rare anomaly. J Indian Acad Oral Med Radiol 2015;27(2):241-4.

[8] Bhatt P, Gupta H, Mathur H, et al. Gemination mandibular third molar - a rare case with use of CBCT in diagnosis and treatment planning. J Indian Acad Oral Med Radiol 2019;31(4):377-81.

[9] Junior OF, de Avila LD, de Silva Sampieri MB, et al. Impacted lower third molar fused with a supernumerary tooth--diagnosis treatment planning using cone-beam computed tomography. Int J Oral Sci 2009;1(4):224-8.

[10] Hamasha AAH, Al-Khateeb T. Prevalence of fused and geminated teeth in Jordanian adults. Quintessence Int 2004;35(7):556-9.

[11] Refoa Y, Rahmati A, Zadsirjan S. Gemination and fusion of mandibular third molar: a case report. Sch J Med Case Rep 2016;4(7):467-8.

[12] Zengin AZ, Celenk P, Gunduz K, et al. Primary double teeth and their effect on permanent successors. Eur J Paediatr Dent 2014;15(3):309-1.

[13] Nandini DB, Deepak BS, Selvamani M, et al. Diagnostic dilemma of a double tooth: a rare case report and review. J Clin Diagn Res 2014;8(1):271-2.

[14] Grover PS, Lorton L. Gemination and twinning in permanent dentition. Oral Surg Oral Med Oral Pathol 1985;59(3):313-8.

[15] Menon PV, Zachariah RK, Kumar LKS, et al. An unusual case of gemination in mandibular supernumerary tooth: a case report. Int J Sci Study 2014;2(2):84-6.

[16] Venkatesh A, Goel S, Wadhwan V, Bansal V. Gemination of a mandibular third molar: a rare case report. SRM J Res Dent Sci 2016;7(2):121-3.

[17] Jain AA, Yeluri R, Munshi AK. Gemination or fusion? A diagnostic dilemma. Dentistry 2014;4(2):196.

[18] Guerisoli DM, de Souza RA, de Sousa Neto MD, et al. External and internal anatomy of third molars. Braz Dent J 1998;9(2):91-4.

[19] Sidow SJ, West LA, Liewehr FR, et al. Root canal morphology of human maxillary and mandibular third molars. J Endod 2000;26(11):675-8.

[20] Asha ML, Ghorai L, Reddy C, et al. Double teeth- a rare case of mandibular third molar gemination. Int J Maxillofacial Imaging 2016;2(4):133-4.

[21] Mader CL. Fusion of teeth. J Am Dent Assoc 1979;98(1):62-4.

[22] Ather A, Ather H, Sheth SM, et al. Unique case of a geminated supernumerary tooth with trifid crown. Imaging Sci Dent 2012;42(3):197-200.

[23] Bains R, Tikku AP, Chandra A, et al. Gemination: a case report. Asian J Oral Health Allied Sci 2015;5:15-17.

[24] Sekerci AE, Sisman Y, Ekizer A, et al. Prevalence of fusion and gemination in permanent teeth in coppadocia region in Turkey. Pakistan Oral Dent J 2011;31(1):17-22. 